\title{
Floodwater utilisation values of wetland services - a case study in Northeastern China
}

\author{
S. B. Lü̈ ${ }^{1}$, S. G. Xu ${ }^{1}$, and F. Feng ${ }^{2}$ \\ ${ }^{1}$ Institute of Water and Environmental Research, Faculty of Infrastructure Engineering, Dalian University of Technology, \\ Dalian 116024, China \\ ${ }^{2}$ Yellow River Conservancy Technical Institute, Kaifeng 475003, China
}

Correspondence to: S. B. Lü (sblv@ mail.dlut.edu.cn)

Received: 29 November 2010 - Revised: 29 November 2011 - Accepted: 19 December 2011 - Published: 15 February 2012

\begin{abstract}
Water plays a significant role in wetlands. Floodwater utilisation in wetlands brings a wide range of wetland services, from goods production and water regulation to animal protection and aesthetics related to water supply in wetlands. In this study, the floodwater utilisation values of wetland services were estimated within the Momoge wetland and Xianghai wetland in western Jilin province of northeastern China. From 2003 to 2008, the floodwater diverted from the Nenjiang and Tao'er River is 381 million $\mathrm{m}^{3}$, which translates into a monetary value of approximately 1.35 billion RMB in 2008 (RMB: Chinese Currency, RMB $6.80=\mathrm{US} \$ 1$ ), and the ratio of economic value, eco-environmental value, and social value is 1:12:2. Besides the monetary value of the water itself, excessive floodwater utilisation may bring losses to wetlands; the threshold floodwater utilisation volumes in wetlands are discussed. Floodwater utilisation can alleviate water shortages in wetlands, and the evaluation of floodwater utilisation in wetland services in monetary terms is a guide for the effective use of the floodwater resources and for the conservation of wetlands.
\end{abstract}

\section{Introduction}

Wetlands are considered the most biologically diverse of all the types of ecosystems, with the uniqueness characterised by its topography, how the water flows, the area's large size and its variety of habitats (Daniel, 2000). Many wetland properties, such as the wetlands' living species, are dependent upon the quantity and quality of water. In the Charles River Basin, Boston, Massachusetts, the economic value of wetlands was estimated to be between US\$ 37.9 million to US $\$ 46.9$ million per square kilometre, with the water supply value accounting for US\$24.9 million (US\$, 1981) of the total (Thibodeau, 1981). With ample water, wetlands provide abundant goods production and a variety of valuable ecological services, including water purification, filtration, retention of nutrients, flood control, groundwater recharge and providing habitat for a variety of species (Tracy, 2004). But imbalance between supply and demand of water is increasingly becoming a common issue, as is the change of regional climate and the increasing urban and suburb population. Because a large amount of water is used by agriculture and industry, wetlands cannot be supplied water effectively. Therefore, a probe into unconventional water resource utilisation plays an important role in maintaining wetland ecosystems and easing water shortages. Rational floodwater utilisation increases water storage in wetlands, which enables protection of the wetland environment and offers services to local residents. Additionally, wetlands mitigate floods and reduce flood threats to people. The quantification of wetland services enabled by floodwater utilisation can provide the link between wetland value and floodwater, which is advantageous for the sustainable development of wetlands.

The evaluation of wetland ecological services has been researched in the past few decades. Krutilla (1967) divided total wetland value into use and non-use values derived from individuals' preferences. Examples of individual use values are recreation, fishing and bird watching; non-use values include both option value and existence value. Option value involves some kind of uncertainty influencing the individual's choices, and existence value is defined as "the value some individuals place on the knowledge of the mere existence of gifts of nature, even when they will never have or choose an opportunity to experience them in situ". Afterwards, Gren et al. (1994) suggested another classification system: primary and secondary values. The first refers to the structure and build up of an ecosystem and the later is defined as the outputs of the life-support services provided by the wetlands. As for the economic analysis of wetlands, Barbier (1994) assessed tropical wetland benefits 
with a cost-benefit analysis as the methodological approach. Turner et al. (2000) combined the economic valuation, integrated modeling, stakeholder analysis and multi-evaluation that can provide complementary insights into sustainable and welfare-optimizing wetland management and policy. Woodwards and Wui (2001) evaluated the relative value of different wetland services, the sources of bias in wetland valuation and the returns to scale exhibited in wetland values with the techniques of bivariate meta-analysis and multivariate metaanalysis. Some attempts have been made to put a monetary measure on the value of wetland services. Raphael and Jaworski (1979) estimated that Michigan's 428 square kilometres of coastal wetlands generated an economic value of US\$ 121005 per square kilometre for a direct annual gross of US\$51.8 million. Employing both a willingness-to-pay and an energy analysis, the value of an average acre of natural wetland in Louisiana is US\$ $0.60-1.58$ million per square kilometre (assuming an $8 \%$ discount rate) to US\$2.224.20 million per square kilometre (assuming a $3 \%$ discount rate) (Costanza et al., 1989). Stevens et al. (1995) used the contingent valuation survey technique to estimate the total economic value of wetland preservation in New England and the aggregate value was estimated to range between 242 and 313 million dollars per year. Costanza et al. (1997) estimated the economic value of 17 ecosystem services (including gas regulation, climate regulation, disturbance regulation, water regulation, water supply, erosion control and sediment retention, soil formation, nutrient cycling, waste treatment, pollination, biological control, refugia, food production, raw material, genetic resources, recreation and culture) for 16 biomes of global ecosystem services, such as coastal regions, forest, wetlands, and cropland, with per year values ranging from US\$ 16 trillion to as high as US\$ 54 trillion. Subsequently, Chen and Zhang (2000) estimated the value of Chinese ecosystem services to be 7.783 billon RMB yr ${ }^{-1}$ in 1994 (RMB: Chinese Currency, RMB 8.72=US\$1). This estimate showed that wetlands, which accounted for only $1.65 \%$ of the total land area, provided $47.71 \%$ of the total ecosystem benefits. Then Xin and Xiao (2002) calculated the Panjin wetland ecosystem services to be 6.21 billion RMB, which 1.2 times the local Gross Domestic Product (GDP). Afterwards, the value of the Panjin wetland, the Zhalong wetland, the Poyang lake ecosystem, and the Yellow river natural protectorate in China were all assessed (Xin and Xiao, 2002; Cui, 2002, 2004; Yang et al., 2009).

The majority of the wetland service studies focused on the value of all the wetland services; little attention was devoted to the water contribution to wetland value, especially in the case of wetland water shortage. Furthermore, there is more research on the ecosystem value in specific regions for a given year, which ignores the dynamic change of wetland values corresponding to environmental and hydrological transformation. Finally, if the floodwater utilisation volume is larger than wetland storage capacity, it may lead to the death of animals and plants in wetlands due to long-term flood soaking. In this case, the floodwater utilisation values are converted into losses. How to identify the threshold of the floodwater utilisation volume needed to provide the maximum contributions at the minimum loss of wetland services is also a problem that cannot be neglected. Emphasizing the practice of floodwater utilisation in wetlands, this study addresses these issues.

The main objective of this paper is to assess the effects of floodwater utilisation for a range of wetland services. Several steps are taken towards the objective. First, the study area and floodwater utilisation are introduced. Then the classification of wetland values under the effect of floodwater utilisation is presented. Thereafter, the assessment methods are described and applied in the study area. Finally, the threshold of floodwater volume use in wetlands is quantified to provide a guide for safe utilisation of floodwater in the future.

\section{Background description}

\subsection{Study area}

The Momoge wetland and the Xianghai wetland are situated in western Jilin province of northeastern China. The Momoge wetland $\left(45^{\circ} 28^{\prime}-46^{\circ} 18^{\prime} \mathrm{N}-122^{\circ} 17^{\prime}-124^{\circ} 43^{\prime} \mathrm{E}\right)$ is located on the right side of Nenjiang and covers about $1440 \mathrm{~km}^{2}$; the main wetland types include water wetland, carex wetland, reed swamp wetland and seepweed wetland. The Xianghai wetland $\left(44^{\circ} 55^{\prime}-49^{\circ} 05^{\prime} \mathrm{N}-122^{\circ} 05^{\prime}-\right.$ $\left.122^{\circ} 31^{\prime} \mathrm{E}\right)$ is located downstream of the Huolin River, and the types of wetland are reservoirs, lakes and marshes. The wetland encompasses an area of $360 \mathrm{~km}^{2}$ and includes a water area of $124 \mathrm{~km}^{2}$ and a freshwater swamp area of $236 \mathrm{~km}^{2}$. These two wetlands are the National Nature Reserves and they are known for their unique scenery and abundant species, including the red-crown crane and swan. Consequently, the wetlands are important for tourism and conservation as well as the gas regulation, flood mitigation and so on.

The Jilin province has a temperate monsoon climate and the rainy season is during the summer from June to September. Climatic characteristics have led to permanent drought in the Jilin province. In 1998, western Jilin province suffered the largest flood ever recorded and the frequency of flooding has reached once in a hundred years. The flood resulted in direct economic loss of 8.40 billion RMB that affected an area of $7552 \mathrm{~km}^{2}$ and a population of 0.87 million. Although the 1998 flood caused economic and social losses, it had some positive impact by increasing water storage in the wetlands, which alleviates drought. But since then, the flood flow continued to be lower than average and western Jilin province remains subject to drought. Especially the Huolin River, as a seasonal river, could not provide the minimum water volume for the Xianghai wetland to protect it from shrinkage and environment deterioration. 
Table 1. Floodwater utilisation volume and wetlands area from 2003 to 2008.

\begin{tabular}{|c|c|c|c|c|c|c|c|c|}
\hline Wetland & \multicolumn{2}{|c|}{ Influence factor } & 2003 & 2004 & 2005 & 2006 & 2007 & 2008 \\
\hline & \multicolumn{2}{|c|}{ Floodwater volume $10^{8} \mathrm{~m}^{3}$} & 0.50 & 0.15 & 0.40 & 0.25 & 0.13 & 0.32 \\
\hline \multirow{4}{*}{ Momoge wetland } & \multirow{3}{*}{ Area $10^{2} \mathrm{~km}^{2}$} & Reed field & 0.85 & 0 & 0.13 & 0.08 & 0.01 & 0.11 \\
\hline & & Grazing field & 1.20 & 0 & 0.30 & 0.13 & 0.07 & 0.16 \\
\hline & & Fishery breeding & 0.40 & 0.11 & 0.28 & 0.17 & 0.09 & 0.23 \\
\hline & \multicolumn{2}{|c|}{ Floodwater volume $10^{8} \mathrm{~m}^{3}$} & 0.60 & 0.83 & 0.20 & 0.15 & 0.08 & 0.20 \\
\hline \multirow{3}{*}{ Xianghai wetland } & \multirow{3}{*}{ Area $10^{2} \mathrm{~km}^{2}$} & Reed field & 0.55 & 0.55 & 0.14 & 0.11 & 0.06 & 0.13 \\
\hline & & Grazing field & 0.84 & 0.80 & 0.13 & 0.09 & 0.05 & 0.11 \\
\hline & & Fishery breeding & 0.17 & 0.17 & 0.11 & 0.08 & 0.04 & 0.10 \\
\hline
\end{tabular}

Table 2. Wetland services and functions evaluated in this study.

\begin{tabular}{llll}
\hline Type & Value & Services & Functions \\
\hline Direct value & Economic value & Goods production & Production of reeds, grazing and fish \\
\hline \multirow{2}{*}{ Indirect value } & \multirow{2}{*}{ Eco-environmental value } & $\begin{array}{l}\text { Fas regulation } \\
\text { Water purification }\end{array}$ & $\begin{array}{l}\text { Carbon fixation, oxygen supply and greenhouse effect } \\
\text { Waste treatment and pollution control }\end{array}$ \\
& & Habitat & Habitat for resident and migratory species \\
\hline \multirow{2}{*}{ Social value } & Recreation & Wetland and eco-tourism \\
& & Culture & Artistic, educational, spiritual and scientific values of wetland \\
\hline
\end{tabular}

\subsection{Floodwater utilisation practice}

The Nenjiang and the Tao'er River are the two main rivers flowing through western Jilin province. The average runoff of the Nenjiang and the Tao'er River are 21.7 billion $\mathrm{m}^{3}$ and 1.19 billion $\mathrm{m}^{3}$, respectively, and over $80 \%$ of the runoff is generated in the flood season (from July to October) (Feng et al., 2010). The analysis of the hydro-information of the Nenjiang and the Tao'er River show a remarkable difference between the two rivers with respect to runoff discharge and flow processes (Xu et al., 2005). The compensation of the flood season and the dry season of the two rivers makes it possible to import floodwater into the wetlands. As a result, the floodwater of the Nenjiang and the Tao'er River is diverted into irrigation systems, wetlands and reservoirs. The Baishatan pump station is an important passage for importing the Nenjiang floodwater to the Momoge wetland, and the Longhuatu project can divert the Tao'er River floodwater into the Xianghai wetland (see Fig. 1). Through water replenishment, the wetlands area increases and the values of floodwater utilisation can be evaluated. Considering the diverse working capacity and the annual flood flow of the Nenjiang and the Tao'er River during the flood season from 2003 to 2008, the floodwater volume diverted into the wetlands and added to the wetlands areas is shown in Table 1.

\section{Classification and methods of wetland floodwater utilisation values}

Wetlands not only offer abundant goods for humans, but also provide significant value ranging from water regulation and purification to recreation and animal protection. It is difficult to list all of the functions provided by wetlands, much less to quantify the value of each function. In an attempt to describe and quantify wetland values simply, a classification of values (direct value and indirect value) is suggested that is based on whether the outputs are brought into the marketplace. Direct value refers to the economic value that can be measured by the market price of the output. Indirect value is defined as the ecological value and social value. Although these two values are not priced on current markets, they must be considered. In this study, we focus on the value generated by floodwater utilisation, with the selection of services from wetlands based on the evaluation of local needs and the available data. Table 2 provides the services and functions assessed in the Momoge and Xianghai wetlands.

The purpose of the value estimation is to quantify the traded and non-traded value that people receive from the wetlands and to enhance the social cognition of wetlands. The assessment of floodwater utilisation value of wetland services provides the theoretical basis to aid in the 


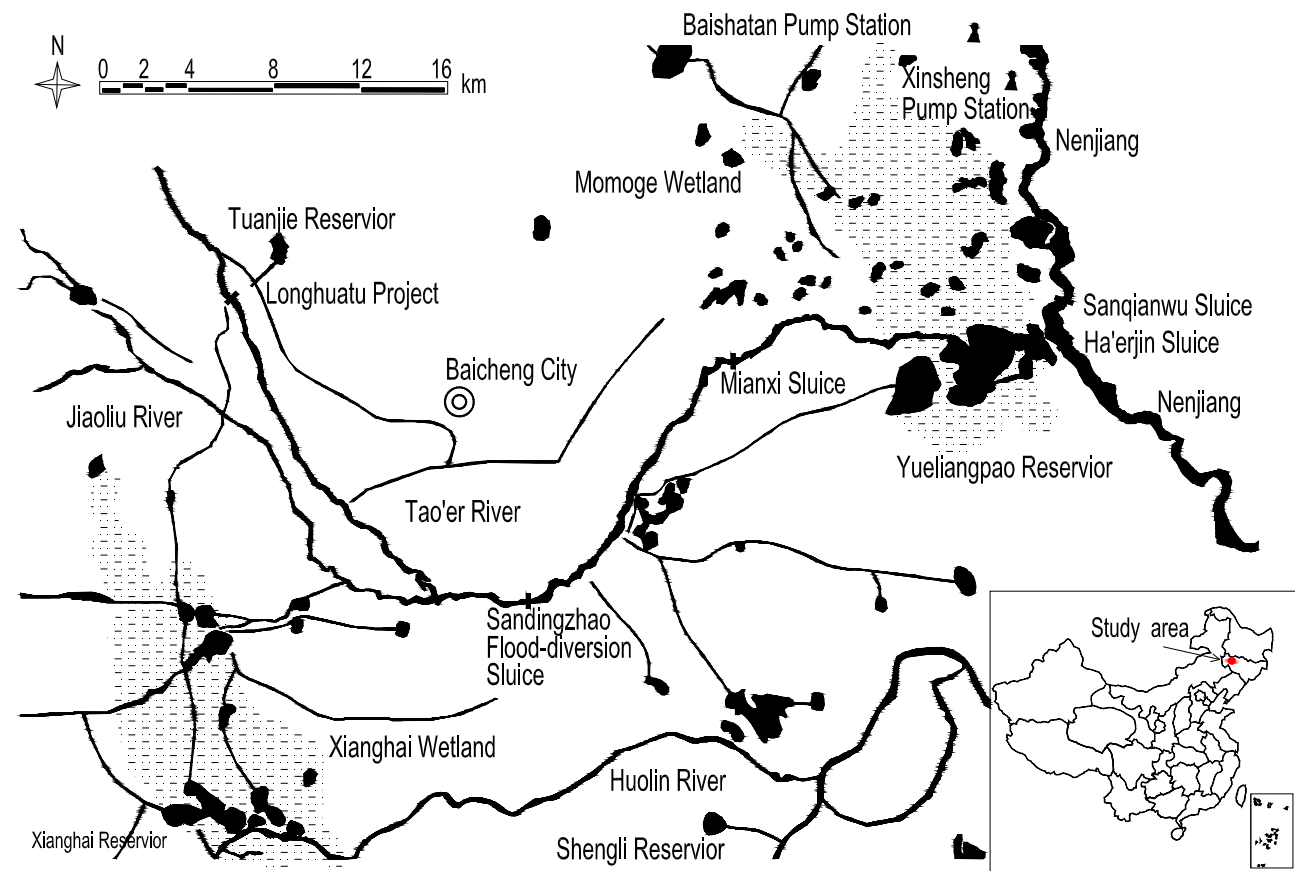

Fig. 1. Diversion works of wetlands and floodwater utilisation.

decision-making regarding the rational utilisation of floodwater and sustainable development of wetlands. Several evaluation techniques are used in this study, such as market prices, the production function method, the substitute cost method and the fixed parameter method. The evaluation of wetland services and functions are presented below.

\subsection{Goods production $\left(\mathrm{V}_{1}\right)$}

With the function-demand coupling method, the main outputs of the Momoge and Xianghai wetlands are reeds, grazing and fish (Du, 2009). This value can be measured through market prices that are used to value the benefits associated with changes in quantity and quality of goods that are treated in markets (Ekin, 2006).

$V_{1}=\sum_{i=1}^{n} A_{i} \cdot Y_{i} \cdot P_{i}-\sum_{i=1}^{n} W_{i}$

where $V_{1}$ is the goods production value; $i$ is the counter for the good which is valued; $A_{i}$ is the increased area of $\operatorname{good} i ; Y_{i}$ is the yield of $\operatorname{good} i ; P_{i}$ and $W_{i}$ are the market price and the cost of good $i$, respectively. In the Momoge and Xianghai wetlands, the yields of reeds, grazing and fish are $375000 \mathrm{~kg} \mathrm{~km}^{-2}, 225000 \mathrm{~kg} \mathrm{~km}^{-2}$, and $21000 \mathrm{~kg} \mathrm{~km}^{-2}$, respectively; the market unit prices are $360 \mathrm{RMB} \mathrm{t}^{-1}, 0.5 \mathrm{RMB} \mathrm{kg}^{-1}$, and $8 \mathrm{RMB} \mathrm{kg}^{-1}$, respectively; and the costs are $60000 \mathrm{RMB} \mathrm{km}^{-2}, 0.2 \mathrm{RMB} \mathrm{kg}^{-1}$, and $1.4 \mathrm{RMB} \mathrm{kg}^{-1}$, respectively.

\subsection{Gas regulation $\left(\mathrm{V}_{2}\right)$}

Wetland gas regulation factors consist of carbon fixation, oxygen supply and the emission of greenhouse gases. The first two terms have positive influence while the third has negative influence. Only by considering all of them can the gas regulation of a wetland be correctly valued. The production function method can be used in this evaluation, which lists out the functional relationship between inputs and outputs. One example is the functional relationship between dry material (such as amylase) and carbon dioxide in the photosynthesis cycle. Plants can fix carbon and supply oxygen through the photosynthesis cycle as described in the reaction equation below.

$$
\begin{aligned}
6 \mathrm{CO}_{2}(264 \mathrm{~g})+ & 6 \mathrm{H}_{2} \mathrm{O}(108 \mathrm{~g}) \rightarrow \mathrm{C}_{6} \mathrm{H}_{12} \mathrm{O}_{6}(180 \mathrm{~g}) \\
+6 \mathrm{O}_{2}(192 \mathrm{~g}) & \rightarrow \text { Amylase }(162 \mathrm{~g})
\end{aligned}
$$

- Carbon fixation: according to the photosynthesis equation, wetland plants absorb $264 \mathrm{~g}$ of $\mathrm{CO}_{2}$ for each $162 \mathrm{~g}$ of dry material produced; in other words, wetland plants need $1.63 \mathrm{~g} \mathrm{CO}_{2}$ to form $1 \mathrm{~g}$ dry material. The primary plant present in the Momoge and Xianghai wetlands is reeds, and the unit price of carbon fixation by reeds is $770 \mathrm{RMBt}^{-1}$, which is determined by the average of the Sweden carbon tax and the China afforestation cost (Cui, 2004).

- Oxygen supply: the photosynthesis equation shows that producing $1 \mathrm{~g}$ of dry matter releases $1.2 \mathrm{~g} \mathrm{O}_{2}$. For 
the unit price of oxygen, we choose the average of the afforestation cost $\left(352.93 \mathrm{RMB} \mathrm{t}^{-1}\right)$ and the industrial oxygen cost $\left(400 \mathrm{RMB} \mathrm{t}^{-1}\right)$. The afforestation cost is the cost of growing forests that can supply the same amount of oxygen with wetlands, and the industrial oxygen cost is the cost of producing oxygen via an industrial process (Ouyang, 1999).

- Emission of greenhouse gases: the primary greenhouse gases are $\mathrm{CH}_{4}$ and $\mathrm{N}_{2} \mathrm{O}$, and the value ascribed to them depends on the gas emission flux. Because the of lacking related experimental data, we adopted the emission flux in the Liao River delta, which is located in northeast China, to be the same as the emission from the Momoge and the Xianghai wetlands (Huang, 2001). After an observation period of 195 days, Huang obtained the emission flux and total emission of $\mathrm{CH}_{4}$ and $\mathrm{N}_{2} \mathrm{O}$ in a reed field. The results showed that the average emission flux of $\mathrm{CH}_{4}$ was $0.52 \mathrm{mg} \mathrm{m}^{-2} \cdot \mathrm{h}$ and the total emission was $27.1 \times 10^{4} \mathrm{kgC}$, and the average emission flux and emission of $\mathrm{N}_{2} \mathrm{O}$ were $29 \mathrm{mg} \mathrm{m}^{2} \cdot \mathrm{h}$ and $1.3 \times 10^{4} \mathrm{kgN}$, respectively. According to the increased reed area of wetlands by floodwater utilisation, the value of the emission of greenhouse gases is calculated by the value of $\mathrm{CH}_{4}$ gas $\left(0.946 \mathrm{RMB} \mathrm{kg}^{-1}\right)$ and $\mathrm{N}_{2} \mathrm{O}$ gas $\left(25.284 \mathrm{RMB} \mathrm{kg}^{-1}\right)$.

\subsection{Flood mitigation $\left(V_{3}\right)$}

Wetland soil has large porosity and high permeability and can absorb and reserve floodwater, leading to an increase in the amount of water storage and the ability to mitigate floods (Ju, 2009). The temporal and spatial redistribution of floodwater can be used in agricultural irrigation, environmental and domestic water supply, and groundwater recharge among other uses. The substitute cost method is used to estimate the value of particular wetland services by calculating the lowest cost provision of the same service by a "next-best" alternative. The method is readily applicable to estimate the value of the flood mitigation service provided by wetlands. Wetlands can be compared to an alternative such as man-made reservoirs. Man-made reservoirs are suitable for cost-comparison because they also reduce the damage from flood and act as a water supply. The construction capital of reservoirs can be a substitute for the value of wetland flood mitigation. By using the investment in reservoir construction from 1988 to 2004 in China, a conclusion is drawn that the investment capital is $0.08 \mathrm{\$} \mathrm{m}^{-3}$ (unchangeable price in 2004) (Jiang, 2007). So the value of flood mitigation is the volume of floodwater stored by the wetland multiplied by the unit capital. The volume of flood mitigation is determined by the difference in storage capacity in pre- and post-wetland floodwater utilisation in a flood season.

\subsection{Water purification $\left(\mathrm{V}_{4}\right)$}

Wetlands remove pollutants from urban and agricultural runoff by means of plants absorbing toxicants, agricultural insecticides and heavy metals. The reeds can absorb, metabolize and decompose pollutants effectively. A study indicated that the decontaminating ability of reeds for arsenic, iron, manganese and lead are $96.06 \%, 92.78 \%$, $94.54 \%$, and $80.18 \%$, respectively (Fu, 2007). The Momoge and the Xianghai wetlands both have abundant reed resources. Toxic substances are removed when the reed is mowed to purify wetland water. We refer to the research of Xin (2001) for the value of water purification of reed fields is $113477 \mathrm{RMB} \mathrm{km}^{-2}$ in order to determine the water purification value of the reeds in the Momoge and Xianghai wetlands.

\subsection{Habitat $\left(V_{5}\right)$}

The wetlands provide growth as well as overwintering grounds for resident and migratory species. The Momoge and the Xianghai wetlands are rich in species resources, such as Grus japonensis and Ciconia nigra. Costanza et al. (1997) determined the habitat value of wetlands to be US\$ $30400 \mathrm{~km}^{-2}\left(251410 \mathrm{RMB} \mathrm{km}^{-2}\right)$. But different countries have different amounts of precipitation in different habitats, for example, the developed countries have higher precipitation than the developing countries. So we introduce the social development stage coefficient $L(\mathrm{Li}, 2002)$ to characterise the different development stages of a country, and the coefficient is presented in formula (3). Then we use $L$ multiplied by the fixed parameter $251410 \mathrm{RMB} \mathrm{km}^{-2}$ to calculate the habitat value of the Momoge and Xianghai wetlands, in formula (3)

$L=\frac{1}{1+e^{\left(3-1 / E_{n}\right)}}$

where $E_{n}$ is the Engel coefficient, which refers to the proportion of residents' food expenses relative to the total living expenses.

\subsection{Recreation $\left(V_{6}\right)$}

Floodwater utilisation helps prevent wetland shrinkage and ecological degradation, thereby promoting tourism. On the basis of the local government bulletin, the primary income from tourism comes from the ecological-tourism of the wetlands, where people travel to the wetlands to hunt, fish or watch wildlife. The tourism bureau only provided detailed information about the number of trips to wetlands and the cost of those trips. So in this study, due to the data limitation, we used the travel cost from the tourism bureau to determine the recreational value of the Momoge and Xianghai wetlands. 
Table 3. Floodwater utilisation value of wetland services from 2003 to 2008 ( $\left.10^{4} \mathrm{RMB}\right)$.

\begin{tabular}{lllllllll}
\hline Wetland & Value & Services & 2003 & 2004 & 2005 & 2006 & 2007 & 2008 \\
\hline & Economic Value & $\mathrm{V}_{1}$ & 2001.900 & 0 & 688.080 & 383.370 & 179.490 & 509.280 \\
\hline \multirow{3}{*}{ Momoge wetland } & & $\mathrm{V}_{2}$ & 2484.118 & 0 & 379.923 & 233.800 & 29.225 & 321.475 \\
& \multirow{2}{*}{ Eco-environmental Value } & $\mathrm{V}_{3}$ & 11152.000 & 1968.000 & 10496.000 & 6232.000 & 3476.800 & 8003.200 \\
& & $\mathrm{~V}_{4}$ & 964.554 & 0 & 147.520 & 90.782 & 11.348 & 124.825 \\
& & $\mathrm{~V}_{5}$ & 915.824 & 573.625 & 1152.394 & 902.074 & 462.907 & 1489.412 \\
\hline \multirow{3}{*}{ Social Value } & $\mathrm{V}_{6}$ & 845.913 & 321.013 & 1000.276 & 961.825 & 673.298 & 2036.726 \\
& & $\mathrm{~V}_{7}$ & 649.400 & 191.000 & 496.600 & 305.600 & 152.800 & 420.200 \\
\hline \multirow{3}{*}{ Xianghai wetland } & \multirow{2}{*}{ Economic Value } & $\mathrm{V}_{1}$ & 1215.120 & 1188.120 & 345.210 & 254.130 & 134.190 & 310.350 \\
& \multirow{2}{*}{ Eco-environmental Value } & $\mathrm{V}_{3}$ & 8528.000 & 7412.800 & 2624.000 & 1968.000 & 1049.600 & 2624.000 \\
& & $\mathrm{~V}_{4}$ & 624.124 & 624.124 & 158.868 & 124.825 & 68.086 & 147.520 \\
& & $\mathrm{~V}_{5}$ & 1514.079 & 3000.355 & 567.421 & 578.634 & 312.246 & 857.876 \\
\hline & \multirow{2}{*}{ Social Value } & $\mathrm{V}_{6}$ & 995.192 & 1797.672 & 538.610 & 601.140 & 504.974 & 1296.099 \\
& & $\mathrm{~V}_{7}$ & 764.000 & 1069.600 & 267.400 & 191.000 & 114.600 & 267.400 \\
\hline
\end{tabular}

$\mathrm{V}_{1}$ : goods production; $\mathrm{V}_{2}$ : gas regulation; $\mathrm{V}_{3}$ : flood mitigation; $\mathrm{V}_{4}$ : water purification; $\mathrm{V}_{5}:$ habitat; $\mathrm{V}_{6}:$ recreation; $\mathrm{V}_{7}:$ culture

\subsection{Culture $\left(\mathrm{V}_{7}\right)$}

The cultural value refers to the artistic, aesthetic, spiritual, educational and scientific values of wetlands. Generally speaking, this part of the value is estimated by the research investment or the actual cost of the research. The Momoge and Xianghai wetlands are not undergoing related studies at this time; therefore, this value is difficult to estimate, due to the limited data and the lagging effect of the culture value. Therefore, the average value of scientific research in the unit area of the wetland ecosystem in China (38 $200 \mathrm{RMB} \mathrm{km}^{-2}$ ) is used to estimate the culture value (Xin and Xiao, 2002).

\section{Results}

Using the methods mentioned above, the values of wetlands services are shown in Table 3.

It is clear that the total floodwater utilisation values demonstrate the enormous benefit of wetland services. In order to compare the value in different years (horizontally) and different services (vertically) in the table, a time factor is taken into account. We use a compound interest calculation to convert the wetland values of different years into 2008 prices by assuming a $6 \%$ discount rate. During floodwater utilisation from 2003 to 2008 , the overall value is 1.35 billion RMB via wetland-diverted floodwater totaling 381 million $\mathrm{m}^{3}$ from the Nenjiang and Tao'er River. Then, we use the value of floodwater per cubic metre that we estimate to be $3.55 \mathrm{RMB}$. The majority of this value that we could determine is not included in a market system, such as gas regulation (more than 99.86 million RMB). About half of the estimated total value comes from flood mitigation (about 0.78 billion RMB), which is 8 times more than the goods production value.

\section{Analysis and discussion}

In this study, the values of floodwater utilisation in wetlands are evaluated. Wetlands perform many potentially valuable functions, especially in indirect value such as in eco-environmental and social terms. An integrated floodwater utilisation value of wetland services research suggests that a combination of economic value, eco-environmental value and social value can provide complementary insight into sustainable water utilisation and wetland development. Based on the value estimates, the ratio of the three values is 1:12:2 and the large eco-environmental value is highlighted by the environmental regulation function of wetlands, also described as "Earth's Kidneys". The indirect value is 14 times that of the direct value. Although the indirect value is not embodied in the accounting system of a state or region, it is irresponsible and unsustainable to exploit wetlands just for economic benefits. The relationship between the value of the wetlands and the floodwater utilisation volume (see Figs. 2 and 3) shows a positive correlation, which demonstrates that water is a decisive component of wetland services and that floodwater utilisation can effectively improve the comprehensive value. The trend of eco-environmental value has a high similarity with flood volume, which shows the prominent effect of floodwater utilisation in the environmental maintenance of wetlands; while subject to local policies and social cognition, the values of economy and society are less immediate than eco-environmental value. But increasing the water resources by floodwater utilisation improves the economic and social development for the arid areas of the future. 


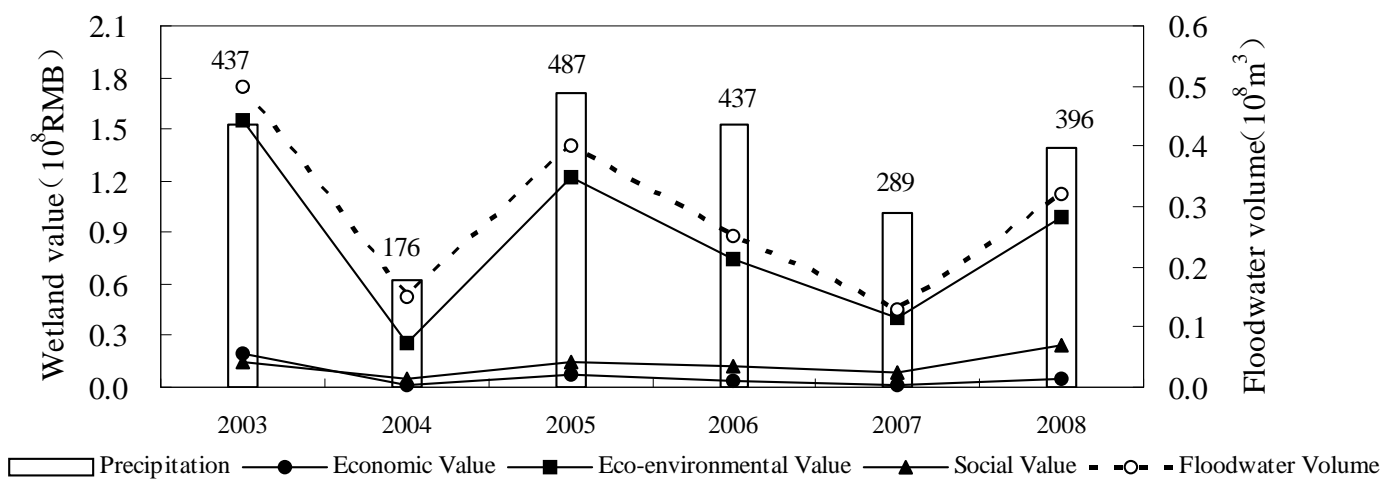

Fig. 2. Relationship between the Momoge Wetland value and the floodwater volume.

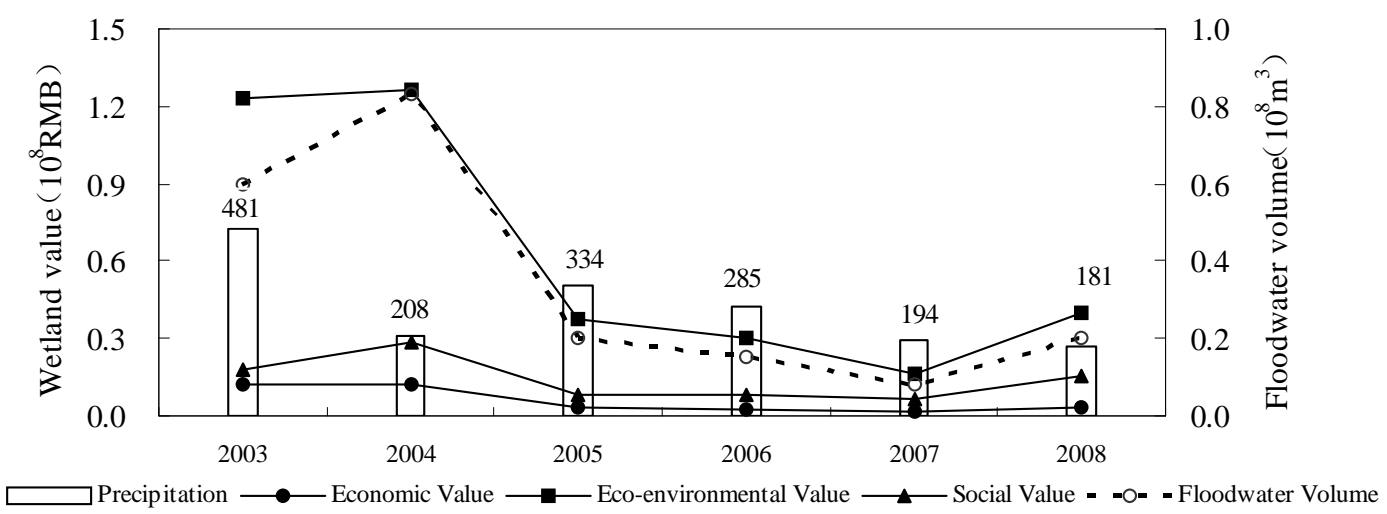

Fig. 3. Relationship between the Xianghai Wetland value and the floodwater volume.

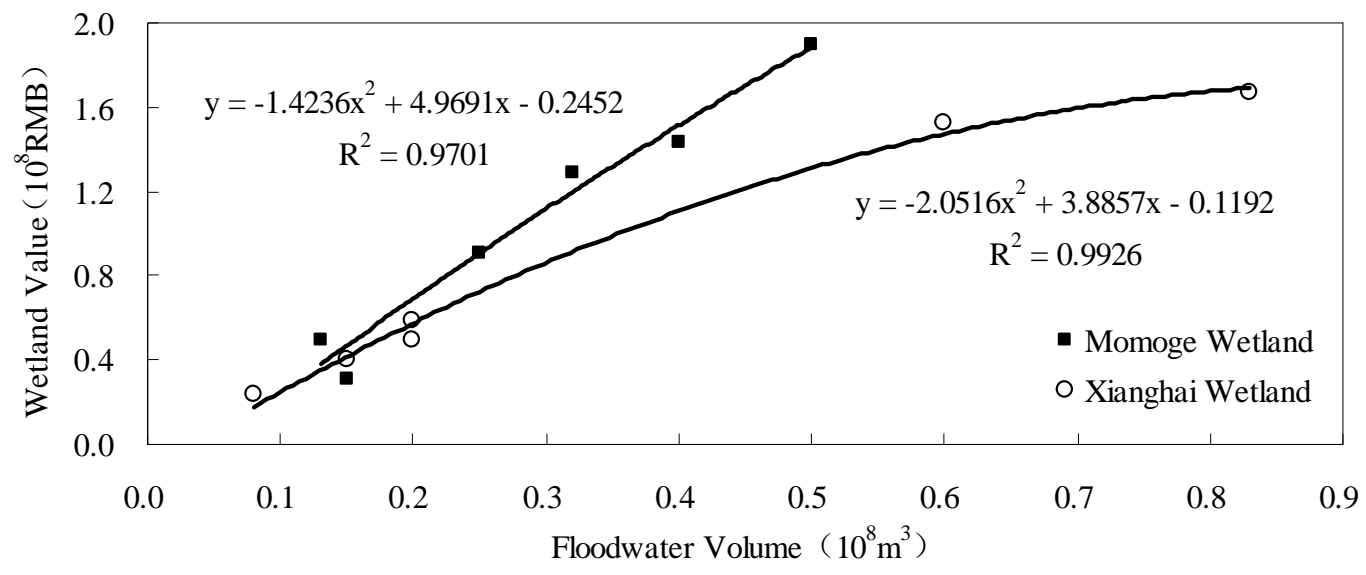

Fig. 4. Fitting curve of wetland value versus floodwater volume. 
The floodwater utilisation volume is affected, to a great extent, by the level of precipitation (Figs. 2 and 3 mark the precipitation in the form of a histogram, and the data units is $\mathrm{mm}$ ). But in 2004, the Xianghai wetland shows prominent value in the case of low precipitation. The reason for this value under low precipitation is the emergency water dispatch from the Chaersen reservoir in the upper Tao'er River that was implemented to maintain the ecological water of the Xianghai wetland. Therefore, complete water diversion works are as important as reasonable floodwater dispatch to fully utilise floodwater.

Unlike conventional water resources, excessive floodwater utilisation may lead to losses as a result of long-term flood soaking. Although floodwater utilisation in the study area did not produce losses during 2003 to 2008, the negative effects to wetlands may occur when high-frequency flooding occurs in the future. Taking the floodwater utilisation volume as the abscissa and the corresponding value as the ordinate, the fitting curves of the Momoge and Xianghai wetlands are obtained, as shown in Fig. 4. From the polynomial fitting curves, we can see that the value decreases when the floodwater utilisation volume reaches a certain value. The polynomial correlation coefficients reach 0.9701 and 0.9926 , which show that the value and volume are highly correlated and that the results are reliable. With the calculation of fitting polynomials, the threshold of floodwater utilisation volumes of wetlands are approximately 174.52 million $\mathrm{m}^{3}$ in the Momoge wetland and 94.69 million $\mathrm{m}^{3}$ in the Xianghai wetland. In order to obtain the objective of "maximum value and minimum loss", performing the threshold analysis for a practical situation is essential for optimal floodwater utilisation.

Value acquisition is inseparable from the earlier investment. To ensure the ecological restoration of wetlands, the investment from the government and the relevant departments has gradually increased. For example, from 2000 to 2007 , Jilin province invested 0.275 billion RMB to improve the infrastructure conditions of nature reserves. Due to the lagging effect of hydraulic engineering investments (Wan, 1989), the comparison between the investment from 2000 to 2007 and the value we estimated from 2003 to 2008 has a certain significance that shows the cost-benefit ratio was relatively prominent.

\section{Conclusions}

Considering the effects of floodwater utilisation in wetlands, we estimated the value of the Momoge and Xianghai wetlands in western Jilin province of northeastern China from 2003 to 2008, which expanded the static value estimation in a certain year into the continuous dynamic research. The estimate of floodwater utilisation value of wetland services accounts for the indirect or potential wetland value and provides an aid for decision-making regarding wetland protection and management. Floodwater utilisation is an effective measure to alleviate shortages in water resources, but the risks of floodwater utilisation should not be ignored. The determination of the threshold floodwater utilisation volume provides a theoretical reference for further floodwater utilisation in order to obtain the maximum benefits from these ecosystems.

The selection of wetland services is restricted to the wetland type. It is difficult to evaluate wetland value because of the differences of natural conditions, management pattern and social cognition. Therefore, this case study has guiding significance for western Jilin province while acts only as a reference value for other wetlands. Undeniably, the lack of basic data and quantified techniques makes the estimate one that could not reflect actual situations. In light of this, we suggest that the local relevant departments should perform related experimental studies and statistical surveys with simultaneous floodwater utilisation practice, which would enable the accurate assessment of the floodwater utilisation value of wetland services. As both wetland ecosystem services and water resources become more stressed and scarce in the future, the value of wetland floodwater utilisation will increase.

Acknowledgements. The authors are grateful for the financial support from the 11th Five Years Key Programmes for Science and Technology Development of China (No. 2006BAB14B05).

Edited by: F. Guzzetti

Reviewed by: W. Dragoni and two other anonymous referees

\section{References}

Barbier E. B.: Valuing Environmental Functions: Tropical Wetlands, Land Econ., 70, 155-173, 1994.

Chen, Z. X. and Zhang, X. S.: Value of Chinese Ecosystem Benefits, Chinese Sci. Bull., 45, 17-22, 2000.

Costanza R., Farber S. C., and Maxwell, J.: Valuation and Management of Wetland Ecosystems, Ecol. Econ., 1, 335-361, 1989.

Costanza, R., d'Arge, R., Groot, R. D., Farber S., Grasso M., Hannon, B., Limburg, K., Naeem, S., O’Neill, R. V., Paruelo, J., Raskin, R. G., Sutton, P., and Belt, M. V. D.: The value of the world's ecosystem services and natural capital, Nature, 387, 253-260, 1997.

Cui, L. J.: Assessment on Zhalong wetland value, J. Nat. Resour., 17, 451-456, 2002.

Cui, L. J.: Evaluation of functions of Poyang Lake ecosystem, Chinese J. Ecol., 23, 47-51, 2004.

Daniel, P. L.: Modeling the biophysical and social dynamics of a 'River of Grass': a challenge for hydroinformatics, J. Hydroinform., 2, 207-217, 2002.

Du, L. J.: Benefit path analysis and quantitative calculation of regional flood resources utilisation of Baicheng city, Dalian University of Technology, 36-38, 2009.

Ekin, B., Katia, K., and Phoebe, K.: Using economic valuation techniques to inform water resources management: A survey and critical appraisal of available techniques and an application, Sci. Total. Environ., 365, 105-122, 2006. 
Feng, F., Xu, S. G., Liu, J. W., Liu, D., and Wu, B.: Comprehensive benefit of flood resources utilisation through dynamic successive fuzzy evaluation model: A case study, Sci. China Ser. E., 53, 529-538, 2010.

Fu, Q., Xie, Y. G., and Wang, L. Q.: The sustainable research of weland water and soil resources utilisation, Water Conservancy Press, 79 pp., 2007.

Gren, I. M., Folke, C., Turner, K., and Batemen, I.: Primary and secondary values of wetland ecosystems, Environ. Resour. Econ., 4, 55-74, 1994.

Huang, G. H., Li, Y. X., Chen, G. X., Yang, Y. C., and Zhao, C. W.: Influence of environmental factors on $\mathrm{CH}_{4}$ emission from reed wetland, Chinese J. Environ. Sci. 22, 1-5, 2001.

Jiang, M., Lu, X. G., Xu, L. S., Chu, L. J., and Tong, S. Z.: Flood mitigation benefit of wetland soil-A case study in Momoge national reserve in China, Ecol. Econ. 61, 217-223, 2007.

Ju, M. T., Wang, Y. X., and Meng, W. Q.: Wetland Ecosystem Protection and Assessment, Beijing, Chemical Industry Press, 9299, 2009.

Krutilla, J. V.: Conservation Reconsidered, Am. Econ. Rev., 57, 777-786, 1967.

Li, J. C.: Value assessment is the key of environmental assessment, China Popul., Resour. Environ., 12, 11-17, 2002.

Ouyan, Z. Y., Wang, X. K., and Miao, H.: A primary study on Chinese terrestrial ecosystem services and their ecological-economic values, Acta. Ecologica. Sinica., 19, 607-613, 1999.

Raphael, C. N. and Jaworski, E.: Economic value of fish, wildlife, and recreation in Michigan's coastal wetlands, Coast. Zone Manage. J., 5, 181-194, 1979.
Stevens, T. H., Benin, S., and Larson J. S.: Public Attitudes and Economic Values for Wetland Preservation in New England, Wetlands, 15, 226-231, 1995.

Thibodeau, F. R.: An Economic Analysis of Wetland Protection, J. Environ. Manage., 12, 19-30, 1981.

Tracy, B. and Stephen, P.: Vauling urban wetlands: A review of non-market valuation studies, Wetlands, 24, 744-755, 2004.

Turner, R. K., Bergh, J., Soderqvist, T., Barendregt, A., Sreaaten, J., Maltby, E., and Ierland, E. C. V.: Ecological-economic analysis of wetlands: scientific integration for management and policy, Ecol. Econ., 35, 7-23, 2000.

Wan, J. N.: The hysteretic nature of investment and the impacts, China Stat., 7, 25-25, 1989.

Woodward, R. T. and Wui, Y. S.: The economic value of wetland services: a meta-analysis, Ecol. Econ., 37, 257-270, 2001.

Xin, K.: Wetland ecosystem service valuation, The Institute of Applied Ecology, CAS, Shenyang, 2001.

Xin, K. and Xiao, D. N.: Wetland Ecosystem Service ValuationA Case Research on Panjin Area, Acta Ecologica. Sinica, 22, 1345-1349, 2002.

Xu, S. G., Liu, J. W., and Chen, L. Y.: Analysis of the compensation effect of lake-reservior-river system in floodwater utilisation, J. Hydraul. Eng., 36, 1359-1364, 2005.

Yang, C. X., Wei, X. F., and Wang, K. N.: The research on the value and function of the wetland ecology in the Yellow River Natural Protectorate in Zhengzhou city, Ecol. Environ., 372-374, 2009. 